\title{
On the Nature of Dendrimer Cross-linking by Ring-Closing Metathesis
}

\author{
James B. Beil, N. Gabriel Lemcoff, and Steven C. Zimmerman* \\ Department of Chemistry, University of Illinois at Urbana-Champaign \\ 600 S. Mathews Avenue, Urbana, IL 61801
}

\section{Supporting Information}

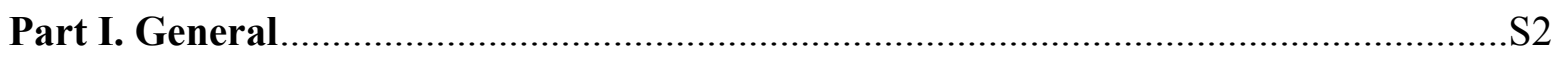

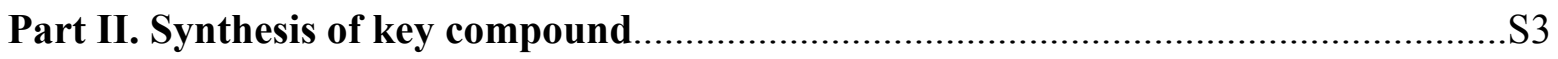

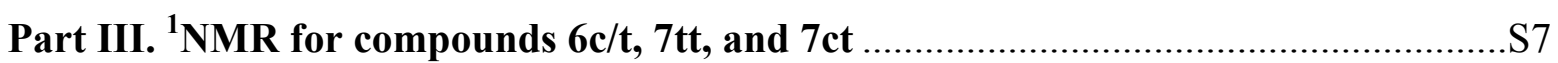

Part IV. MALDI, SEC, and ${ }^{1}$ H NMR data for cross-linking of 1 ...............................S8

Part V. MALDI and SEC data for hydrolysis of cross-linked 1 ................................S9

Part VI. Analysis of relative occurrence of type d cross-links ...................................S10 


\section{Part I. General}

All reactions were performed in an atmosphere of dry nitrogen, unless noted otherwise. Most solvents and reagents used were reagent quality, purchased commercially. THF was distilled over sodium and benzophenone. Column chromatography was performed using Merck 40-63 $\mu \mathrm{m}$ silica and all solvent ratios are v:v.

NMR spectra were acquired at the Varian-Oxford Inova Center for Excellence in NMR Spectroscopy (VOICE) lab at UIUC. ${ }^{1} \mathrm{H}$ spectra were recorded on a Varian Unity 500 or $400 \mathrm{MHz}$ spectrometer. ${ }^{1} \mathrm{H}$ coupling constants are reported in Hertz $(\mathrm{Hz})$. The ${ }^{1} \mathrm{H}$ NMR chemical shifts are referenced to residual protio-solvent peak at $7.26 \mathrm{ppm}$ in chloroform- $d$. Unless stated otherwise, the ${ }^{1} \mathrm{H}$ NMR spectra were acquired in $\mathrm{CDCl}_{3}$.

All mass spectra were obtained in the Mass Spectrometry Laboratory of The School of Chemical Sciences at UIUC. Matrix-assisted laser desorption ionization time-of-flight mass spectra (MALDI-TOF MS) were obtained using a PerSeptive Biosystems Voyager DE-STR spectrometer. Analytical SEC were obtained using a Waters Styragel HR3 triple column (molecular weight range 500-30,000) coupled with Viscotek TDA model 300 triple detector array or on a Waters Styragel HR3 single column with a Hitachi L4000H UV detector using a Hitachi L-6000 pump. SEC molecular weights were calculated using polystyrene standards as calibrates. Preparative SEC was carried out on Bio-Beads S-X1 Beads gel permeation gel 200-400 mesh (Bio-Rad Laboratories) that has exclusion limits from 400-14,000. 


\section{Part II. Synthesis of key compounds}
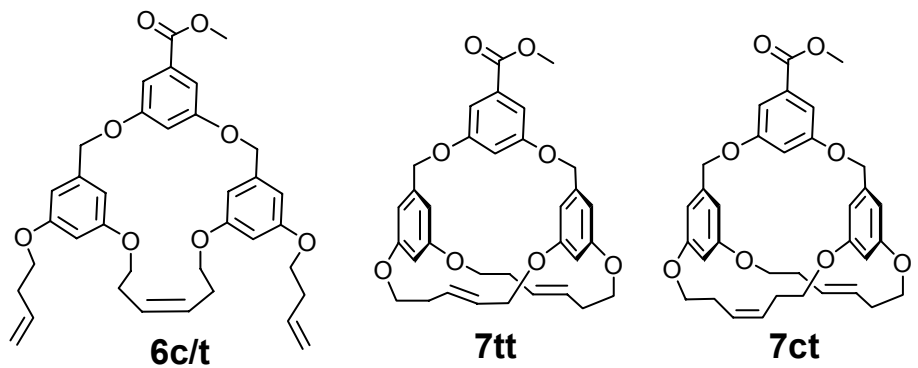

Cross-linked Dendrons 6c/t, 7tt, and 7et. To a solution of $250 \mathrm{mg}(0.4 \mathrm{mmol})$ 3,5bis-(3,5-bis-but-3-enyloxy-benzyloxy)-benzoic acid methyl ester (3) and 2 L benzene was added $40.4 \mathrm{mg}(0.049 \mathrm{mmol})$ Grubbs' first generation catalyst (5). The reaction mixture was stirred at room temperature for 20 hours. $22.2 \mathrm{mg}(0.0269 \mathrm{mmol})$ Grubbs' first generation catalyst (5) was added, and the reaction was allowed to stir at room temperature for 44 hours. The reaction mixture was quenched with $1 \mathrm{~mL}$ of ethyl vinyl ether. Purification using a short silica plug provided a brown compound that was added to $2 \mathrm{~g}$ charcol and $5 \mathrm{~mL}$ dichloromethane and heated to reflux for 30 minutes. Subsequent purification using a short silica plug afforded a white solid. Purification using a silica gel column afforded $91.6 \mathrm{mg}$ of $\mathbf{6 c} / \mathbf{t}$ (38\% yield), $70.2 \mathrm{mg}$ of $7 \mathbf{t t}$ (31\% yield), and $29.3 \mathrm{mg}$ of 7 ct (13\% yield). $\mathbf{6 c} / \mathbf{t}{ }^{1} \mathrm{H}$ NMR $\delta: 7.19(1.5 \mathrm{H}, \mathrm{d}, J=2.35), 7.16$ $(0.5 \mathrm{H}, \mathrm{t}, J=2.13), 6.70(1 \mathrm{H}, \mathrm{t}, J=2.37), 6.58(1 \mathrm{H}, \mathrm{m}), 6.50(2.5 \mathrm{H}, \mathrm{m}), 6.38(0.5 \mathrm{H}, \mathrm{t}, J=$ 2.14), $6.37(1.5 \mathrm{H}, \mathrm{t}, J=2.13), 5.89(2 \mathrm{H}, \mathrm{m}), 5.64(2 \mathrm{H}, \mathrm{m}), 5.16(2 \mathrm{H}, \mathrm{m}), 5.11(2 \mathrm{H}, \mathrm{m})$, $5.05(3 \mathrm{H}, \mathrm{s}), 5.02(1 \mathrm{H}, \mathrm{s}), 3.98(3 \mathrm{H}, \mathrm{t}, J=6.69), 3.97(1 \mathrm{H}, \mathrm{t}, J=6.44), 3.94(4 \mathrm{H}, \mathrm{t}, J=$ 6.37), 3.89 (2H, s), $3.87(0.5 \mathrm{H}, \mathrm{s}), 2.58(1 \mathrm{H}, \mathrm{q}, J=5.96), 2.52(4 \mathrm{H}, \mathrm{dt}, J=6.54,1.24)$, $2.47(3 \mathrm{H}, \mathrm{m}) . \mathrm{MS}(\mathrm{FD}) 600.4(\mathrm{M}) .7 \mathrm{tt}^{1} \mathrm{H}$ NMR $\delta: 7.31(2 \mathrm{H}, \mathrm{d}, J=2.26), 6.17(1 \mathrm{H}, \mathrm{t}, J$ $=2.42), 6.05(4 \mathrm{H}, \mathrm{d}, J=2.10), 6.02(2 \mathrm{H}, \mathrm{t}, J=2.13), 5.60(4 \mathrm{H}, \mathrm{m}), 5.03(4 \mathrm{H}, \mathrm{s}), 3.93$ $(3 \mathrm{H}, \mathrm{s}), 3.78(8 \mathrm{H}, \mathrm{m}), 2.35(8 \mathrm{H}, \mathrm{m})$. MS (FD) $572.4(\mathrm{M}) .7 \mathrm{ct}{ }^{1} \mathrm{H}$ NMR $\delta: 7.29(2 \mathrm{H}, \mathrm{d}, J$ $=2.30), 6.26(1 \mathrm{H}, \mathrm{t}, J=2.06), 6.15(2 \mathrm{H}, \mathrm{m}), 6.11(4 \mathrm{H}, \mathrm{d}, J=1.81), 5.63(2 \mathrm{H}, \mathrm{m}), 5.57$ $(2 \mathrm{H}, \mathrm{m}), 5.03(4 \mathrm{H}, \mathrm{dd}, J=43.1,15.01), 3.92(3 \mathrm{H}, \mathrm{s}), 3.79(8 \mathrm{H}, \mathrm{m}), 2.46(4 \mathrm{H}, \mathrm{hep}, J=$ 6.4), 2.35 (4H, m). MS (FD) 572.4 (M).

Cross-linked Dendron 9a. To a solution of $900 \mathrm{mg}(0.675 \mathrm{mmol})$ of G3-dendron 4 and $12 \mathrm{~L}$ benzene was added $150 \mathrm{mg}(0.19 \mathrm{mmol})$ Grubbs' first generation catalyst (5). 
The reaction mixture was stirred at room temperature for 48 hours. The reaction mixture was quenched with $1 \mathrm{~mL}$ of ethyl vinyl ether. Purification using a silica gel plug (first filtration of the benzene, followed by washing with ethyl acetate and evaporation of the solvent), followed by purification by preparative SEC afforded $600 \mathrm{mg}$ of fully crosslinked 9a (73\% yield) and $150 \mathrm{mg}$ of material with 3 crosslinks (18\%). MS (MALDI-TOF) $1243.3\left(\mathrm{M}+\mathrm{Na}^{+}\right), 1259.2\left(\mathrm{M}+\mathrm{K}^{+}\right) . \quad \mathrm{SEC} \mathrm{MW}_{\mathrm{PS}}=690$.

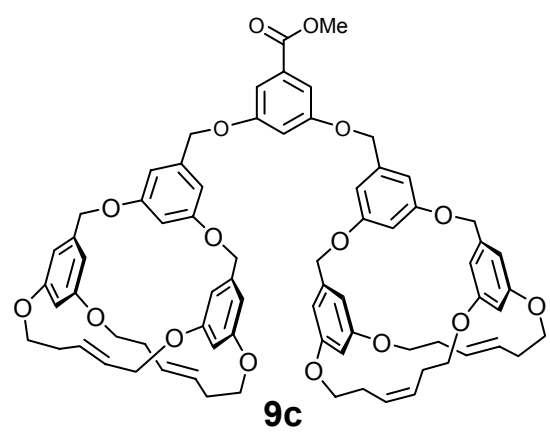

Cross-linked dendron 9c. To $20 \mathrm{mg}(0.035 \mathrm{mmol})$ of a 1:1 mixture of $7 \mathrm{tt}: 7 \mathrm{ct}$ and 7 $\mathrm{mL}$ of THF was added $10 \mathrm{mg}(0.025 \mathrm{mmol}) \mathrm{LiAlH}_{4}$. The reaction was stirred at room temperature for 20 hours. $25 \mathrm{~mL}$ of water and $25 \mathrm{~mL}$ of $3 \mathrm{M}$ aqueous $\mathrm{HCl}$ were added sequentially. THF was removed under reduced pressure, and the aqueous layer was extracted with three $50 \mathrm{~mL}$ portions of diethyl ether. The organic extracts were combined, dried with sodium sulfate, filtered, and dried under reduced pressure to afford $17.4 \mathrm{mg}$ of a white solid. $89 \%$ yield. ${ }^{1} \mathrm{H}$ NMR $\delta: 6.64(1.6 \mathrm{H}, \mathrm{m}), 6.42-6.56(1 \mathrm{H}, \mathrm{m})$, 6.24-6.38 (0.4H, m), 6.10-6.19 (1.4H, m), $6.08(2 \mathrm{H}, \mathrm{d}, J=2.14), 6.03(1.4 \mathrm{H}, \mathrm{t}, J=2.05)$, $6.37(0.5 \mathrm{H}, \mathrm{t}, J=2.13), 5.60(4 \mathrm{H}, \mathrm{m}), 5.00(4 \mathrm{H}, \mathrm{m}), 4.55-4.70(2 \mathrm{H}, \mathrm{m}), 3.70-4.00(8 \mathrm{H}$, $\mathrm{m}), 2.41-2.60(3 \mathrm{H}, \mathrm{m}), 2.35(4 \mathrm{H}, \mathrm{m})$. To the resulting mixture was added $2.7 \mathrm{mg}(0.016$ mol) 3,5-dihydroxybenzoic acid methyl ester $(\mathbf{8}), 9.5 \quad \mathrm{mg} \quad(0.036 \mathrm{mmol})$ triphenylphosphine, $25 \mathrm{~mL}$ THF, and finally $7 \mu \mathrm{L}(0.044 \mathrm{mmol})$ diethylazodicarboxylate (DEAD). The reaction mixture was allowed to stir at room temperature for 20 hours. 50 $\mathrm{mL}$ of water was added, and the THF was removed under reduced pressure. The aqueous layer was extracted with three $50 \mathrm{~mL}$ portions of diethyl ether. The organic extracts were combined, washed with $50 \mathrm{~mL}$ of water, $50 \mathrm{~mL}$ of $5 \%$ aqueous $\mathrm{KOH}$ solution, and finally with $50 \mathrm{~mL}$ of water. The organic layer was evacuated and purified by preparative TLC 
to afford $9 \mathrm{mg}$ of a white solid. $46 \%$ yield. ${ }^{1} \mathrm{H}$ NMR $\delta: 7.33(2 \mathrm{H}, \mathrm{m}), 6.87(1 \mathrm{H}, \mathrm{m}), 6.71$ $(4 \mathrm{H}, \mathrm{m}), 5.90-6.20(14 \mathrm{H}, \mathrm{m}), 5.60(8 \mathrm{H}, \mathrm{m}), 5.02(12 \mathrm{H}, \mathrm{m}), 3.92(3 \mathrm{H}, \mathrm{m}), 3.70-3.90(16 \mathrm{H}$, m), $2.47(3 \mathrm{H}, \mathrm{m}), 2.35(13 \mathrm{H}, \mathrm{m})$. MS (MALDI-TOF) $1221\left(\mathrm{M}+\mathrm{H}^{+}\right), 1244.01\left(\mathrm{M}+\mathrm{Na}^{+}\right)$, $1259.72\left(\mathrm{M}+\mathrm{K}^{+}\right) . \quad \mathrm{SEC} \mathrm{MW} \mathrm{PS}=840$.

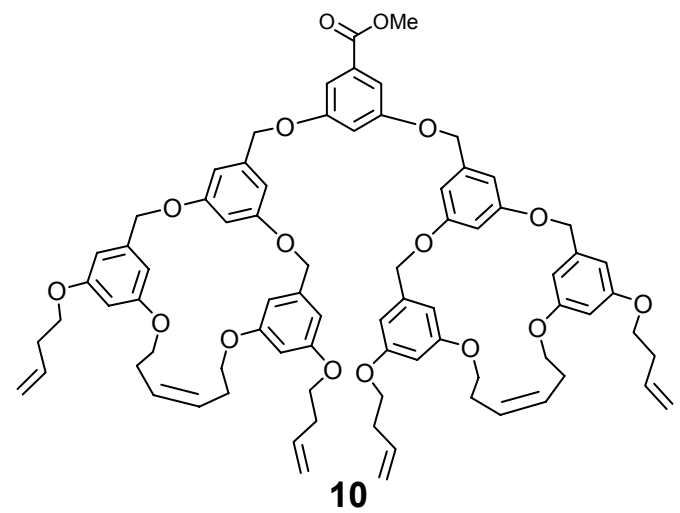

Cross-linked dendron 10. To a mixture of $75 \mathrm{mg}(0.125 \mathrm{mmol}) \mathbf{6 c} / \mathbf{t}$ and $8 \mathrm{~mL}$ of THF was added $31 \mathrm{mg}(0.815 \mathrm{mmol}) \mathrm{LAH}$. The reaction was stirred at room temperature for 20 hours. $25 \mathrm{~mL}$ of water and $25 \mathrm{~mL}$ of $3 \mathrm{M}$ aqueous $\mathrm{HCl}$ were added sequentially. THF was removed under reduced pressure, and the aqueous layer was extracted with three $50 \mathrm{~mL}$ portions of diethyl ether. The organic extracts were combined, dried with sodium sulfate, filtered, and dried under reduced pressure to afford $50 \mathrm{mg}$ of a white solid. $68 \%$ yield. ${ }^{1} \mathrm{H}$ NMR $\delta: 6.58(1.4 \mathrm{H}, \mathrm{m}), 6.44-6.56(5.4 \mathrm{H}, \mathrm{m}), 6.34-6.38(2 \mathrm{H}, \mathrm{m})$, $5.88(2 \mathrm{H}, \mathrm{m}), 5.63(2 \mathrm{H}, \mathrm{m}), 5.16(2 \mathrm{H}, \mathrm{m}), 5.10(2 \mathrm{H}, \mathrm{m}), 5.01(3 \mathrm{H}, \mathrm{s}), 4.98(1 \mathrm{H}, \mathrm{s}), 4.58$ $(1.4 \mathrm{H}, \mathrm{s}), 4.55(0.5 \mathrm{H}, \mathrm{s}), 3.90-4.00(8 \mathrm{H}, \mathrm{m}), 2.57(1 \mathrm{H}, \mathrm{q}, J=5.99), 2.52(4 \mathrm{H}, \mathrm{dt}, J=6.56$, 1.21), $2.46(3 \mathrm{H}, \mathrm{m})$. To the resulting mixture was added $26.5 \mathrm{mg}(0.101 \mathrm{mmol})$ triphenylphosphine, $25 \mathrm{~mL}$ THF, and finally $19 \mu \mathrm{L} \quad\left(\begin{array}{llll}0.120 & \mathrm{mmol})\end{array}\right.$ diethylazodicarboxylate (DEAD). The reaction mixture was allowed to stir at room temperature for 24 hours. $50 \mathrm{~mL}$ of water was added, and the THF was removed under reduced pressure. The aqueous layer was extracted with three $50 \mathrm{~mL}$ portions of diethyl ether. The organic extracts were combined, washed with $50 \mathrm{~mL}$ of water, $50 \mathrm{~mL}$ of $5 \%$ aqueous $\mathrm{KOH}$ solution, and finally with $50 \mathrm{~mL}$ of water. The organic layer was evacuated and purified by preparative TLC to afford $30 \mathrm{mg}$ of a white solid. $74 \%$ yield. ${ }^{1} \mathrm{H}$ NMR $\delta: 7.26(2 \mathrm{H}, \mathrm{d}, J=2.16), 6.76(1 \mathrm{H}, \mathrm{m}), 6.58(6 \mathrm{H}, \mathrm{d}, J=1.60), 6.49(7 \mathrm{H}, \mathrm{m})$, 
$6.37(1 \mathrm{H}, \mathrm{t}, J=1.85), 6.35(3 \mathrm{H}, \mathrm{t}, J=1.89) 5.78(4 \mathrm{H}, \mathrm{m}), 5.64(4 \mathrm{H}, \mathrm{m}), 5.45(4 \mathrm{H}, \mathrm{m})$, $5.08(4 \mathrm{H}, \mathrm{m}), 5.01(6 \mathrm{H}, \mathrm{s}), 4.98(2 \mathrm{H}, \mathrm{s}), 4.96(3 \mathrm{H}, \mathrm{s}), 4.93(1 \mathrm{H}, \mathrm{s}), 3.95(16 \mathrm{H}, \mathrm{m}), 3.90$ $(3 \mathrm{H}, \mathrm{s}), 3.70-3.90(16 \mathrm{H}, \mathrm{m}), 2.57(1 \mathrm{H}, \mathrm{q}, J=6.29), 2.51(4 \mathrm{H}, \mathrm{m}), 2.46(3 \mathrm{H}, \mathrm{m})$. MS (MALDI-TOF) $1274.23\left(\mathrm{M}+\mathrm{H}^{+}\right), 1304.01\left(\mathrm{M}+\mathrm{Na}^{+}\right), 1360.08\left(\mathrm{M}+\mathrm{K}^{+}\right) . \quad$ SEC $\mathrm{MW}_{\mathrm{PS}}=$ 1270.

Cross-linked dendron 9b. To a solution of $30 \mathrm{mg}(0.023 \mathrm{mmol})$ of 10 and $2.3 \mathrm{~L}$ benzene was added $7.6 \mathrm{mg}(9.2 \mu \mathrm{mol})$ Grubbs' first generation catalyst (5). The reaction mixture was stirred at room temperature for 20 hours. $5 \mathrm{mg}(6.1 \mu \mathrm{mol})$ Grubbs' first generation catalyst (5) was added. The reaction was allowed to stir at room temperature for 44 hours, and the reaction mixture was quenched with $1 \mathrm{~mL}$ of ethyl vinyl ether. Purification using a short silica plug followed by purification by preparative TLC afforded $26 \mathrm{mg}$ of a white solid. 91\% yield. ${ }^{1} \mathrm{H}$ NMR $\delta: 7.29(1 \mathrm{H}, \mathrm{m}), 6.20-6.80(18 \mathrm{H}$, m), 5.90-6.20 (1.7H, m), $5.60(8 \mathrm{H}, \mathrm{m}), 4.60-5.20$ (12H, m), 3.70-4.00 (19H, m) 2.20-2.60 $(16 \mathrm{H}, \mathrm{m}) . \mathrm{MS}(\mathrm{MALDI}-\mathrm{TOF}) 1246.19\left(\mathrm{M}+\mathrm{Na}^{+}\right), 1261.74\left(\mathrm{M}+\mathrm{K}^{+}\right) . \quad \mathrm{SEC} \mathrm{MW}_{\mathrm{PS}}=730$. 
Part III. ${ }^{1} \mathrm{H}$ NMR for compounds $6 \mathrm{c} / \mathrm{t}$, $7 \mathrm{tt}$, and $7 \mathrm{ct}$
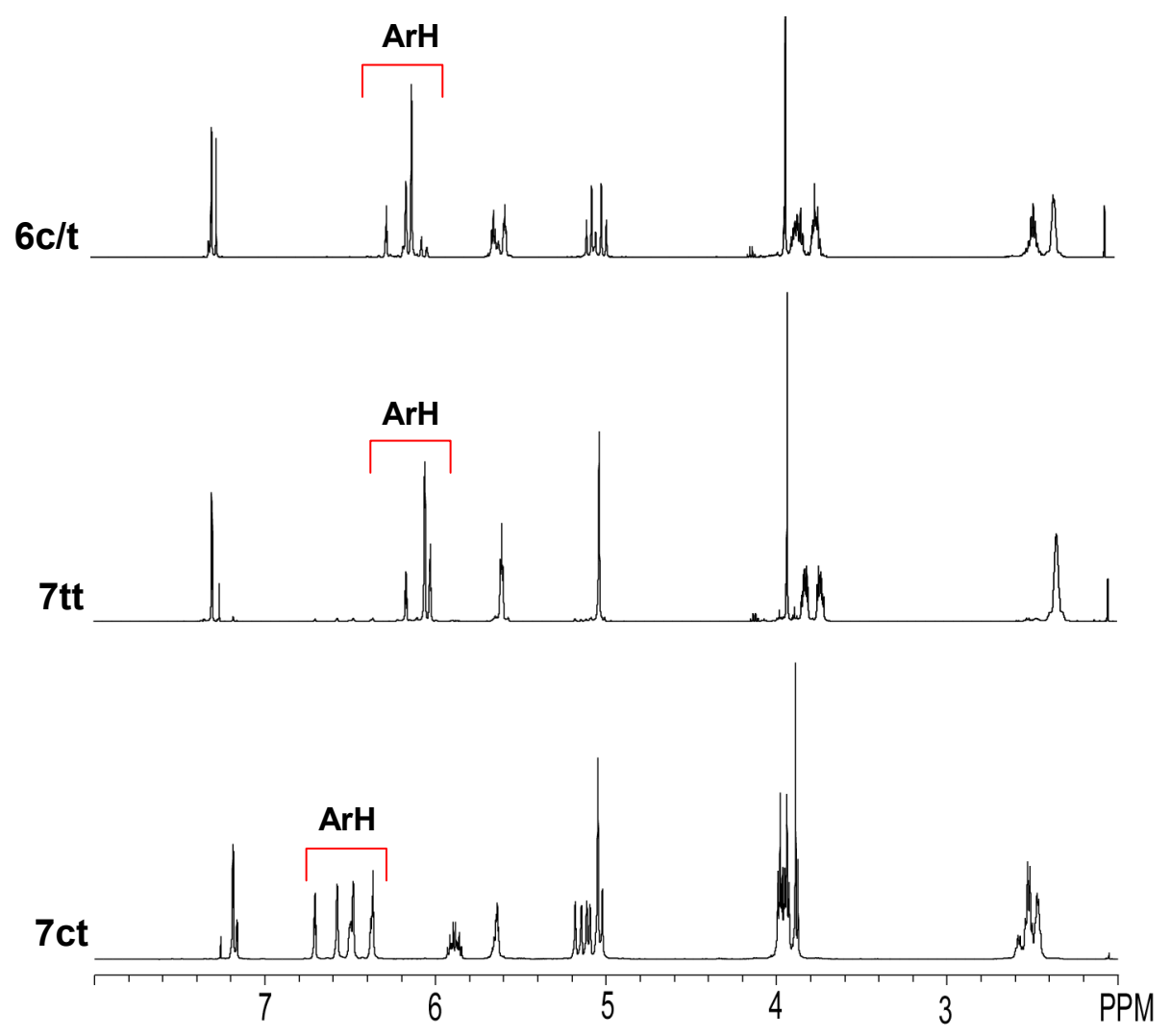

Figure S1. ${ }^{1} \mathrm{H}$ NMR for compounds $\mathbf{6 c / t}, \mathbf{7 t t}$, and $\mathbf{7 c t}$. 


\section{Part IV. ${ }^{1} \mathrm{H}$ NMR and MALDI data for cross-linking of 1}

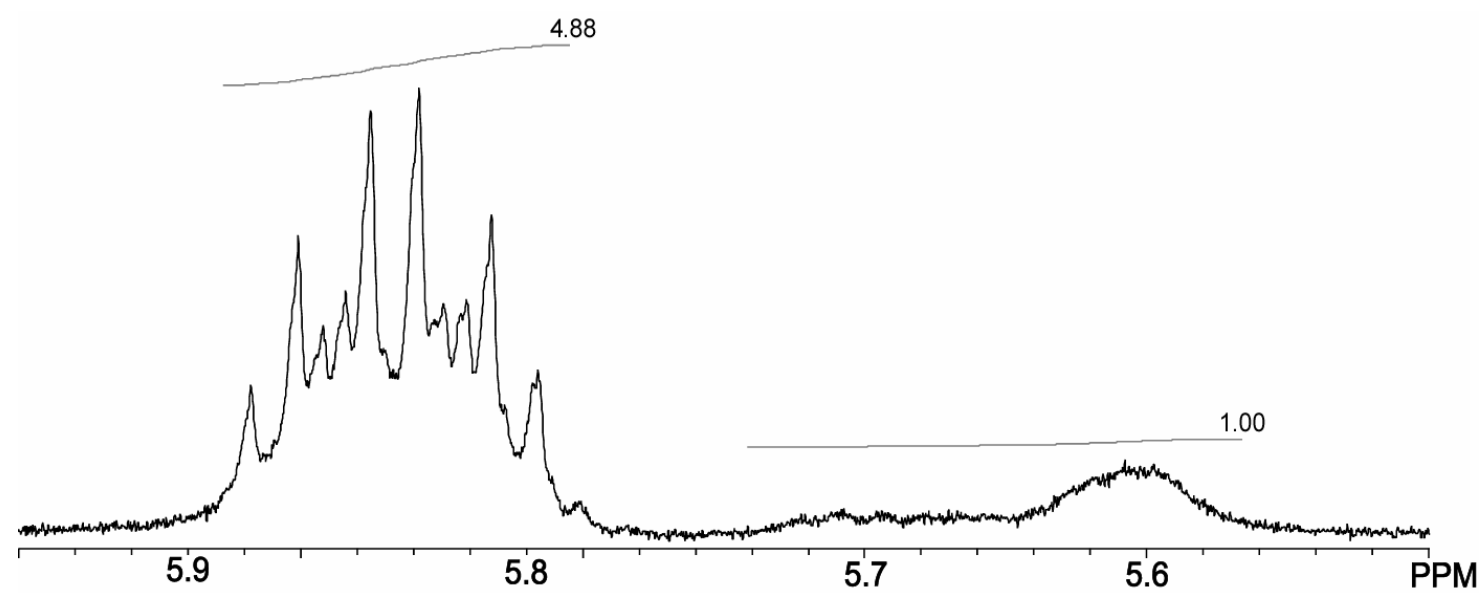

Figure S2. Representative ${ }^{1} \mathrm{H}$ NMR of cross-linked 1 (20 minutes under RCM conditions). The peak area between 5.5-5.8 ppm (cross-linked alkenes) is 17\% of the peak area between 5.8-6.0 ppm (uncross-linked alkenes).

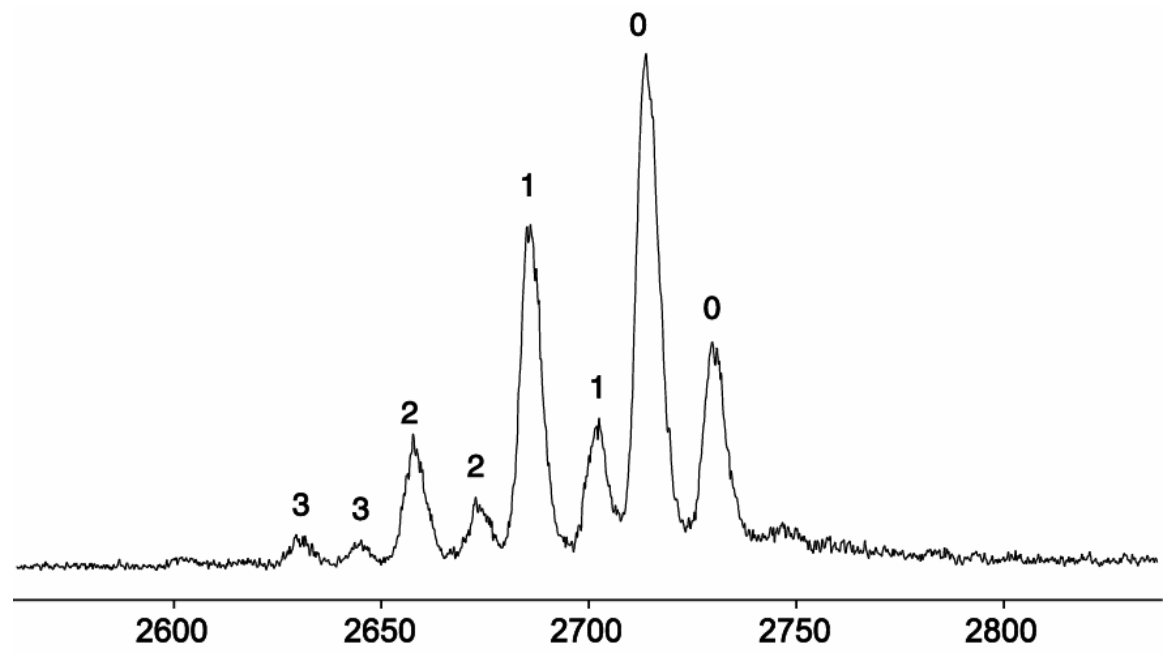

Figure S3. Representative MALDI-TOF MS spectrum for the cross-linking of 1 (5 minutes under $\mathrm{RCM}$ conditions). $\mathrm{Na}^{+}$and $\mathrm{K}^{+}$adduct peaks are labeled with the corresponding number of cross-links. From the peak heights, it was determined that $8 \%$ of the alkenes had reacted. 
Table S1. Comparison of percent cross-linking as determined by MALDI and ${ }^{1} \mathrm{H}$ NMR

\begin{tabular}{cccc}
\hline Reaction time & $\%$ alkenes cross-linked by MALDI & \% alkenes cross-linked by NMR & $\%$ difference \\
\hline $1 \mathrm{~min}$ & 4 & 4 & 0 \\
$5 \mathrm{~min}$ & 8 & 8 & 0 \\
$10 \mathrm{~min}$ & 11 & 12 & 8 \\
$20 \mathrm{~min}$ & 15 & 17 & 12 \\
$30 \mathrm{~min}$ & 18 & 17 & 6 \\
$60 \mathrm{~min}$ & 22 & 23 & 4 \\
$180 \mathrm{~min}$ & 31 & 31 & 0 \\
\hline
\end{tabular}

\section{Part V. MALDI and SEC data for hydrolysis of cross-linked 1}
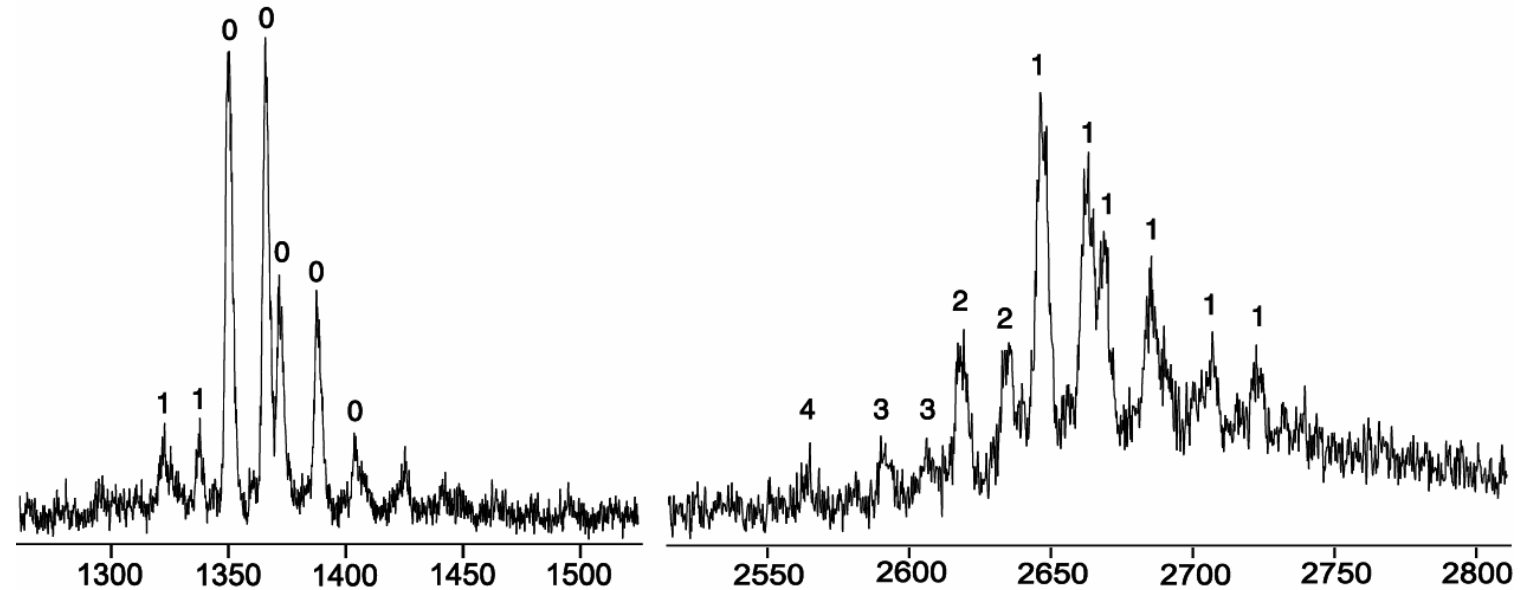

Figure S4. Representative MALDI-TOF MS spectra for the hydrolysis of cross-linked 1. $\mathrm{Na}^{+}$and $\mathrm{K}^{+}$adduct and single salt $\mathrm{Na}^{+}$and $\mathrm{K}^{+}$adduct peaks are labeled with the corresponding number of cross-links. $\mathrm{Na}^{+}$and $\mathrm{K}^{+}$adduct, single salt $\mathrm{Na}^{+}$and $\mathrm{K}^{+}$adduct, and double salt $\mathrm{Na}^{+}$and $\mathrm{K}^{+}$adduct peaks are labeled with the corresponding number of cross-links. 


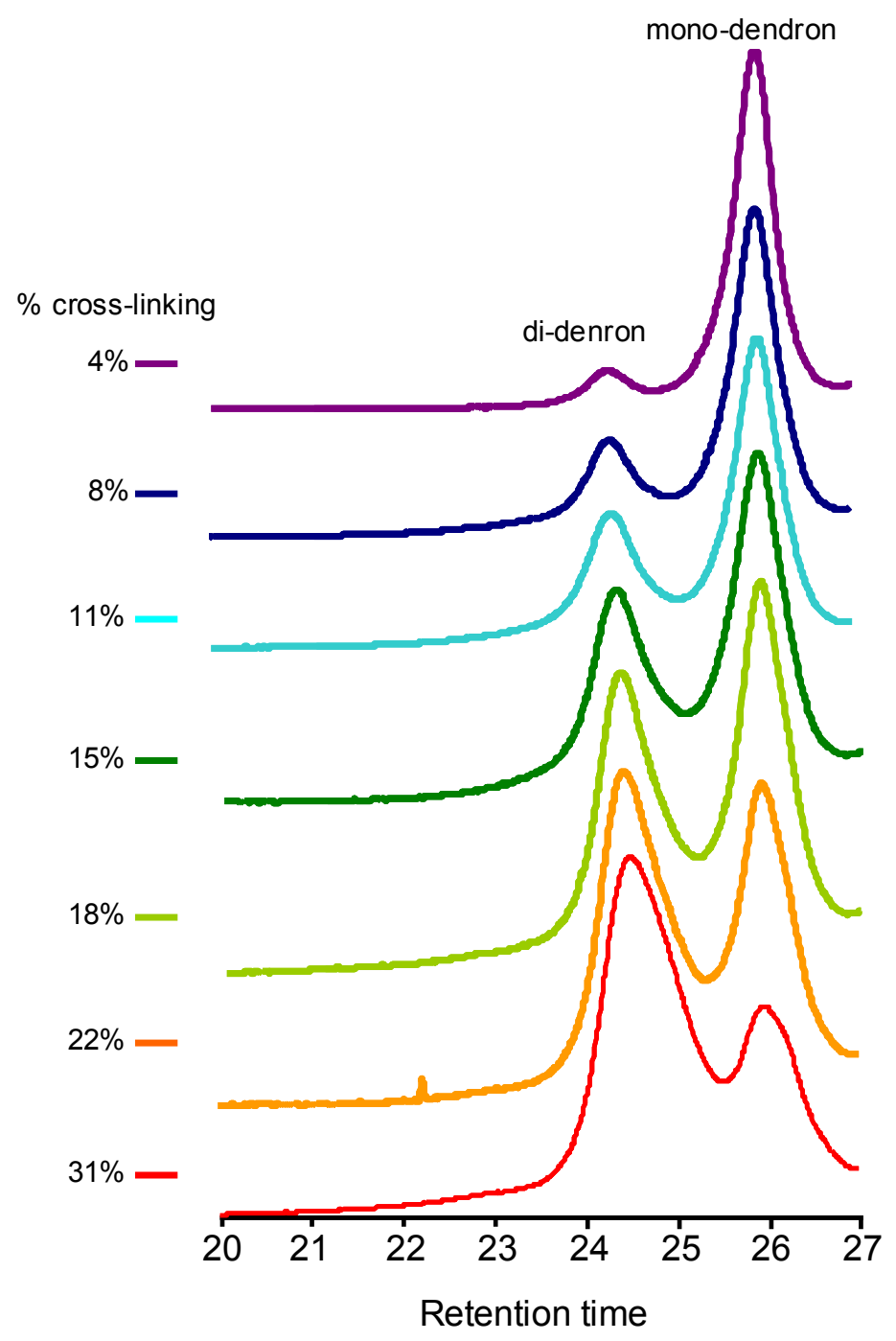

Figure S5. SEC chromatograms for the hydrolysis of cross-linked 1. 


\section{Part VI. Analysis of relative occurrence of type d cross-links}

By analyzing MALDI data for the cross-linking of $\mathbf{1}$, it was possible to calculate the relative amounts of unreacted $\mathbf{1}$, the amount of $\mathbf{1}$ with just one cross-link (Figure S3), and the amount of 1 with more than 1 cross-link. For example, data that was obtained after 5 minutes of reaction time shows that $50 \%$ of 1 remains unreacted, $33 \%$ of 1 had just 1 cross-link, and 17\% of 1 had more than one cross-link (Figure S3, Table 1).

After hydrolysis of cross-linked samples of 1, SEC data were used to determine the ratio of hydrolyzed material that either fragmented to form mono-dendron or remained cross-linked forming di-dendron. Because each molecule of $\mathbf{1}$ with no inter-dendron cross-links will fragment to form two mono-dendron species, and because SEC data was determined using an RI detector (concentration dependent), the SEC ratio of di-dendron to mono-dendron was corrected by multiplying the di-dendron peak by 2. For example, after hydrolysis of the material that had undergone cross-linking for just 1 minute, the SEC mono-dendron:di-dendron ratio was 90:10. The corrected value is $90: 20$ or $82: 18$ (Table 1).

To calculate the fraction of dendrimers that have only 1 cross-link and still form didendron upon hydrolysis, equation S1 was used. Thus, the amount of 1 with more than one cross-link prior to hydrolysis (calculated by MALDI, Figure S3) was subtracted from the corrected amount of di-dendron (calculated by SEC, Figure S5), giving a value for the amount of di-dendron with just one cross-link. The resulting value was divided by the overall amount of $\mathbf{1}$ that has just one cross-link (calculated by MALDI, Figure S3) giving a value for the fraction of dendrimers that have only one cross-link and still stay together to form di-dendrons. Equation 1 is only valid when after hydrolysis, the amount of mono-dendron with more than 1 cross-link (directly observable by MALDI, Figure S4) is insignificant (low degree of cross-linking).

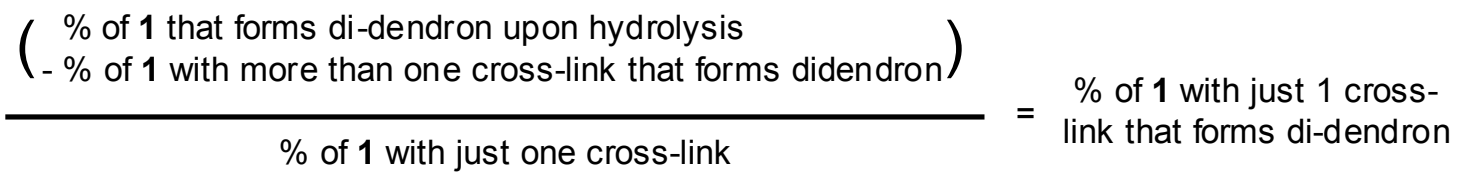

Equation S1. Equation used to calculate the fraction of dendrimers that have only 1 cross-link and still form di-dendron upon hydrolysis 


\section{Example of how Equation S1 was used}

Using the MALDI data after 5 minutes under RCM conditions, the amount of $\mathbf{1}$ with more than 1 cross-link was $17 \%$, and using the corrected SEC data after hydrolysis, the amount of di-dendron was $42 \%$, giving $42-17=25 \%$. The resulting $25 \%$ was divided by the overall percentage of 1 that has just one cross-link (33\%) giving a value of 0.76 for the fraction of dendrimers that have only one cross-link and still stay together to form didendrons (Table 1). 